\title{
Communication
}

\section{Effects of Vitamin B Mixture on Neuropathy in Streptozotocin-Induced Diabetic Rats}

\author{
Katsuhiko SaKitama, Kiyoharu SAITo, Minako AIKAwA, \\ Mika NAGO, and Michio ISHIKAWA ${ }^{1}$ \\ Pharmacology Section, Research Laboratories, Pharmaceuticals Group, \\ Nippon Kayaku Co., Ltd., Kita-ku, Tokyo 115, Japan \\ (Received July 7, 1988)
}

\begin{abstract}
Key Words vitamin B mixture, nerve conduction velocity, diabetic neuropathy, streptozotocin, rats
\end{abstract}

Vitamin $\mathrm{B}$ mixture, especially a mixture of $\mathrm{B}_{1}, \mathrm{~B}_{6}$, and $\mathrm{B}_{12}$, provides beneficial effects when used for the clinical treatment of various types of neuropathy including that in diabetes $(I)$. In diabetic neuropathy, a decrease in nerve conduction velocity (NCV), segmental demyelination in nerve fibers, and an impairment of Schwann cells are observed in peripheral nerves(2). In animal experiments, thickening and degeneration of the myelin sheath are observed in both alloxan and streptozotocin (STZ) diabetic rats, and this demyelination may result in the reduction of NCV observed in diabetic rats (3-5). NCV is used as a major diagnostic and therapeutic index for assessing the function of peripheral nerves in diabetic neuropathy. Iwata et al.(6) and Fukuda et al.(7) reported an ameliorating effect of vitamin B mixture $\left(\mathrm{B}_{1}, \mathrm{~B}_{6}\right.$, and $\left.\mathrm{B}_{12}\right)$ on the decrease in NCV in alloxan diabetic rats. However, there is little information concerning the effects of vitamin B mixture on STZ-induced diabetic neuropathy, which is considered the preferable model for studying severe diabetic peripheral neuropathy $(8)$. Thus, we investigated the effects of daily administration of 3B (a mixture of thiamine disulfide, pyridoxal hydrochloride and aquocobalamin) on STZ-induced diabetic neuropathy using NCV as the index. In accordance with a previous report (9) which demonstrated the favorable effects of a high dose of $3 \mathrm{~B}$ on neuropathy induced by acrylamide, we also adopted a relatively high dose of $3 \mathrm{~B}$.

The experiments were carried out on 3 groups of male Sprague-Dawley rats ( 9 weeks old, $n=14-19$ ). A standard laboratory chow (CRF-1, Charles River) and tap water were always available. Daily intake of vitamin $B_{1}, B_{6}$, and $B_{12}$ from the diet was approximately $1.5,0.5$, and $0.0075 \mathrm{mg}$ per rat, respectively. Two groups were made diabetic by intraveneous injection of $45 \mathrm{mg} / \mathrm{kg} \mathrm{STZ} \mathrm{(Sigma)} \mathrm{dissolved} \mathrm{in}$ citrate buffer ( $\mathrm{pH} 4.1)$ immediately before use. The third group received the citrate

${ }^{1}$ 崎玉克彦, 妻藤清治, 合川美奈子, 名古みか, 石川道雄 
buffer alone as control. One of the STZ-treated groups was treated for 7 weeks with daily intraperitoneal injection of $3 \mathrm{~B}$ [ a mixture of thiamine disulfide $(25 \mathrm{mg} / \mathrm{kg})$, pyridoxal hydrochloride $(50 \mathrm{mg} / \mathrm{kg})$, and aquocobalamin $(0.5 \mathrm{mg} / \mathrm{kg})$ dissolved in solvent (saline containing $0.5 \%$ urea) at a volume of $0.1 \mathrm{ml} / 100 \mathrm{~g}$ body weight]. The other STZ group and controls received daily intraperitoneal injection of the solvent for 7 weeks. In each case, the administration of $3 \mathrm{~B}$ or solvent commenced 7 days after STZ treatment. Plasma glucose was measured once or twice every two weeks by the glucose oxidase method using a glycolyzer (Chugai). Body weight was determined weekly. Diabetic rats were identified 3 days after STZ injection by plasma glucose values above $300 \mathrm{mg} / \mathrm{dl}$. NCV was measured weekly using the tail nerve according to Miyoshi's method (10). Prior to measurement, the rats were lightly anesthetized with ether, and their tails were warmed in a liquid paraffin bath maintained at $37^{\circ} \mathrm{C}$ by a thermoregulator. Two electrodes for stimulation were set along the longitudinal nerve of the tail at a distance of $5 \mathrm{~cm}$, and another electrode was inserted into the tail segmental muscle for recording the evoked action potential. Stimulatory rectangular pulses of $0.3 \mathrm{~ms}$ in duration were delivered from a Nihon Kohden Electrostimulator MSE-3, and the evoked potential was traced on a Nihon Kohden memory oscilloscope VC-10, and recorded on a Watanabe XY recorder WX-4401. NCV was calculated by dividing the distance between the two stimulation electrodes by the difference in the latencies from these electrodes. Statistical analysis was performed using Student's $t$-test or Aspin-Welch procedure.

Hyperglycemia appeared in diabetic rats 3 days after STZ treatment. The NCV of control rats increased with aging, while the increase in NCV of diabetic rats was significantly inhibited from 2 weeks after STZ treatment (Fig. 1). This observation coincides with the results reported by Iwata et al.(6) and Greene et al. (11). The $\mathrm{NICV}$ of the $3 \mathrm{~B}$-treated diabetic rats changed in a similar fashion to that of the diabetic rats until 3 weeks after STZ treatment; thenceforth, the increase in NCV of the $3 \mathrm{~B}$-treated diabetic rats was less suppressed than that of the untreated diabetic rats. The NCV value in the $3 \mathrm{~B}$-treated diabetic rats was significantly faster than that in the untreated diabetic rats at 5 and 7 weeks $(p<0.1)$ and 6 and 8 weeks $(p<0.05)$ after STZ treatment. At 8 weeks, the NCV of $3 \mathrm{~B}$-treated diabetic rats was comparable to that of control rats.

In control rats, blood glucose levels were within normal range and a normal weight gain with aging was observed. In contrast, persistent hyperglycemia and a suppressed weight gain were observed in the diabetic rats throughout the experimental period. At 8 weeks after STZ-treatment, blood glucose levels were $102.9 \pm 1.3$, $472.1 \pm 16.5$, and $452.2 \pm 9.7 \mathrm{mg} / \mathrm{dl}$, for control, diabetic, and 3B-treated diabetic rats, respectively. At this time, the body weights were $483.1 \pm 10.0,322.4 \pm 16.4$, and $309.1 \pm 8.0 \mathrm{~g}$, for control, diabetic, and 3B-treated diabetic rats, respectively. There was no statistical difference between the diabetic and $3 \mathrm{~B}$-treated diabetic rats in these two parameters.

In this study, 3B was found to ameliorate the inhibition of the age-associated increase in NCV in STZ diabetic rats. This occurred without affecting blood glucose 


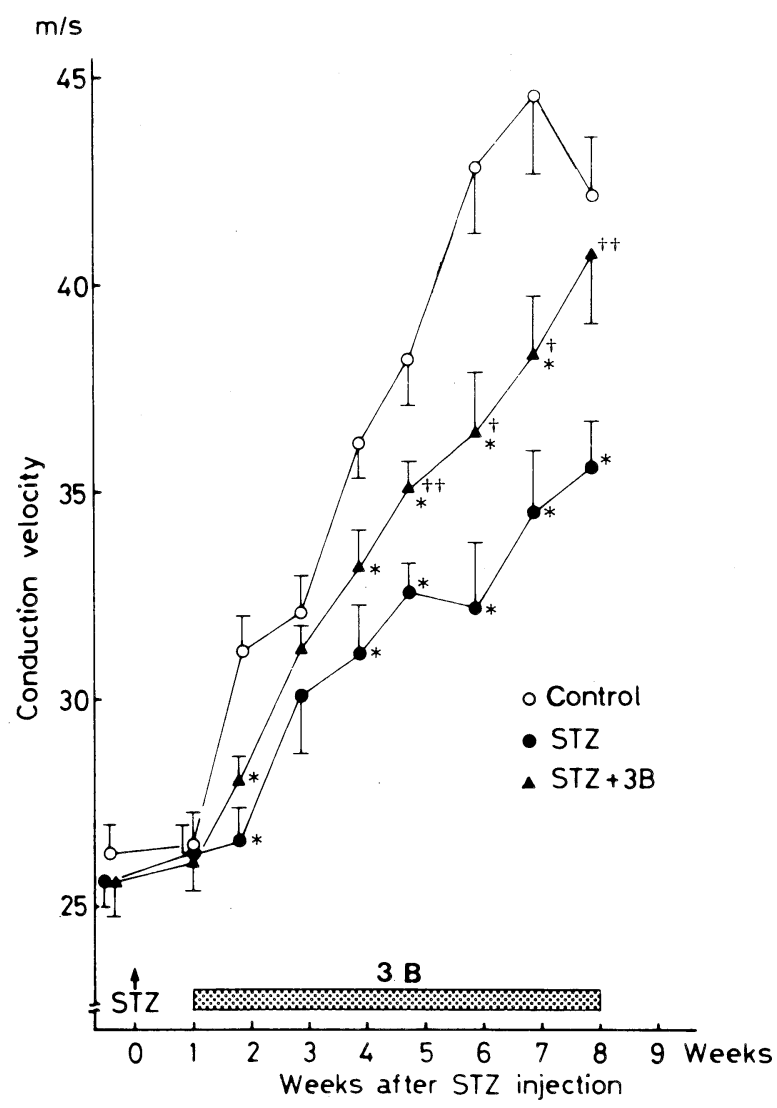

Fig. 1. Changes in tail NCV in non-diabetic control rats, diabetic rats, and 3B-treated diabetic rats. Each point represents the mean with SEM indicated. Rats were rendered diabetic by intraveneous injection of $45 \mathrm{mg} / \mathrm{kg} \mathrm{STZ}$ (arrow). Dotted band indicates the period for daily administration of $3 \mathrm{~B} .{ }^{*} p<0.05 v s$. control rats, $+p<0.1$ and $++p<0.05 v s$. STZ diabetic rats.

levels or body weight. These results suggest $3 \mathrm{~B}$ improved impaired NCV without affecting the diabetes itself as suggested by Fukuda et al.(7). Yagihashi et al. (12) reported that the daily administration of methylcobalamin decreased the incidence of degenerated nerve fibers and suppressed the reduction of myelinated nerve fiber density in STZ diabetic rats. Ikeda et al.(13) also reported that the atrophy of Schwann cells and the incidence of disintegration of the myelin sheath of sciatic nerves observed in alloxan diabetic rats were normalized by daily administration of vitamin B mixture. It is possible that the beneficial effects of vitamin B mixture on the morphological changes described in these studies may be involved in the ameliorative effects which we reported in the present study. Although Yagihashi et al. (5) reported that morphological findings of peripheral nerves seen in the alloxan 
diabetic rats were almost identical with those seen in STZ diabetic rats, the mechanisms underlying the induction of neuropathy in diabetic rats have not been fully understood. The fact that daily administration of vitamin B mixture suppressed the progress of neuropathy in STZ as well as in alloxan diabetic rats might indicate the possibility that there are common mechanisms, which were affected by vitamin B mixture, in the induction or progress of neuropathy in both animal models of diabetes.

These results suggest that daily administration of $3 \mathrm{~B}$ would retard the progress of neuropathy in diabetic patients. Together with the observation that $3 \mathrm{~B}$ also inhibited the progress of another type of neuropathy caused by acrylamide ( 9 ), our study of STZ diabetes supports the probability that $3 \mathrm{~B}$ has favorable effects on various types of neuropathy in man.

\section{REFERENCES}

1) Iida, M., Okada, T., Goto, Y., Baba, M., Emura, Y., Sato, G., Kimura, I., Natori, N., Suzuki, S., and Satoyoshi, E. (1976): A double blind controlled study on the clinical efficacy of Neolamin 3B injection in peripheral neuropathies. Diagnosis Treatment, 1 , 171-178.

2) Thomas, P. K., and Lascelles, R. G. (1965): Schwann-cell abnormalities in diabetic neuropathy. Lancet, 1, 1355.

3) Eliasson, S. G. (1964): Nerve conduction changes in experimental diabetics. J. Clin. Invest., 43, 2353-2358.

4) Preston, G. M. (1967): Peripheral neuropathy in the alloxan diabetic rat. J. Physiol., 189, 49-50.

5) Yagihashi, S., Kudo, K., and Nishihira, M. (1979): Peripheral nerve structures of experimental diabetes rats and the effects of insulin treatment. Tohoku J. Exp. Med., $127,35-44$.

6) Iwata, N., Matsumura, M., and Sakai, Y. (1979): Effects of vitamin B complex in functional changes of the peripheral nerves of alloxan-induced diabetic rats. Folia Pharmacol. Jpn. (in Japanese), 75, 9-21.

7) Fukuda, N., Ikeda, H., Shino, A., Iwatsuka, H., and Nagawa, Y. (1979): Effects of vitamin $\mathrm{B}_{1}, \mathrm{~B}_{6}$ and $\mathrm{B}_{12}$ on the sciatic nerve in alloxan diabetic rats. Vitamins (J. Vitam. Soc. Jpn.), 53, 513-521.

8) Moore, S. A., Peterson, R. G., Felten, D. L., and O'Conner, B. L. (1980): A quantitative comparison of motor and sensory conduction velocities in short- and long-term streptozotocin- and alloxan-diabetic rats. J. Neurol. Sci., 48, 133-152.

9) Shinozaki, H., Ishikawa, M., Adachi, K., Fujii, Y., and Ishii, Y. (1974): Effect of the vitamin B complex on the functional restoration of rat peripheral nerve. Vitamins $(J$. Vitam. Soc. Jpn.), 48, 377-384.

10) Miyoshi, T. (1971): Serial determinations of nerve conduction velocity in normal and alloxanized diabetic rats. Fukuoka Med. J. (in Japanese), 62, 588-603.

11) Greene, D. A., Lewis, R. A., Lattimer, S. A., and Brown, M. J. (1982): Selective effects of myo-inositol administration on sciatic and tibial motor nerve conduction parameters in the streptozotocin-diabetic rat. Diabetes, 31, 573-578.

12) Yagihashi, S., Nishihira, M., Kashiwamura, H., and Tokui, A. (1980): Quantitative 
analysis of the effect of methylcobalamin on the peripheral nerve structures in experimental diabetic neuropathy. Jpn. J. Clin. Pharmacol. Ther. (in Japanese), 11, 131-139.

13) Ikeda, H., Fukuda, N., Shino, A., Iwatsuka, H., and Nagawa, Y. (1979): Potentiating effect of vitamin $B_{6}$ and $B_{12}$ on the ameliorative action of vitamin $B_{1}$ on diabetic disorders of the sciatic nerve in the rat. Vitamins (J. Vitam. Soc. Jpn.), 53, 523-529. 